\title{
A survey of shinty injuries in the Highlands during 1987-88
}

\author{
J.G.B. Maclean, FRCS \\ Orthopaedic Department, Raigmore Hospital, Inverness, Scotland
}

\begin{abstract}
Shinty is an ancient game, related to hurling and hockey, that is played in the Highlands of Scotland. A survey of shinty injuries was carried out during one season. The injury rate and location of injuries is provided. A comparison is made with other ball sports.
\end{abstract}

Keywords: Shinty, injuries, injury rate

\section{Introduction}

A thousand years before Rome was founded or Homer wrote the Odyssey, the Celts of the northern fringe of Europe began to play the root game which has become shinty. In early times, whole armies battled for the ball in a rowdy melee, wielding their camans (clubs or sticks) in sport and exercise rather than in anger. As far as we can tell from surviving illustrations, the stick has altered little down the centuries. The same has been said about the pattern of play by those who do not understand the subtleties of the game.

Shinty is a fast moving and skilfull sport, a legacy most likely of the migration from Ireland into the new Scots nation in the sixth century. Hurling and shinty are cousin sports combining many of the features of lacrosse and hockey. It is the progenitor of the latter and of ice hockey, and both cricket and golf trace some of their origins from a form of the game.

The caman, or shinty stick, is similar in shape to that employed in hockey, but triangular in cross-section. The ball may be struck with any of the three surfaces, and there are no constraints upon how the caman may be swung, irrespective of the proximity of other players.

The ball itself may be played on the ground or in the air. It is slightly smaller than a hockey ball, but more resilient and with a raised seam.

As in most sports, the majority of injuries occur in the tackle. In shinty, tackling can be from either side, from in front or behind, and there are two main types: clicking or hooking, in which the striker's stick is hooked or deflected from behind, and blocking, in which the tackler attempts to block his opponent's

Address for correspondence: Mr Maclean, Orthopaedic Department, Homerton Hospital, Hackney, London

(C) 1989 Butterworth \& Co (Publishers) Ltd

0306-3674/89/030179-04\$03.00 stick from in front. The margin for error is small and the potential for injury is obvious.

Shinty is a purely amateur sport. At present there are 40 clubs in Scotland, fielding 60 teams of 12 players each. These teams compete in two leagues of four divisions each and in various knock-out competitions throughout the season. In spite of its great popularity in the Highlands and the ferocity with which the game is played, there has been no previous survey of shinty injuries.

This paper goes some way to rectifying that omission and as such it is the first quantitative assessment of injuries in shinty. In addition, it compares the injury rate in shinty to those in other amateur sports.

\section{Materials and method}

This survey was conducted between September 1987 and June 1988, thus encompassing the whole of one season. A standard proforma was completed on any player who presented to the accident and emergency departments at Raigmore Hospital (Inverness), the Belford Hospital (Fort William) and the West Highland Hospital (Oban). The patient completed his personal details, player data (club, position) the mechanism of injury and whether or not an infringement took place. The attending doctor then recorded the nature of injury and subsequent treatment.

Before calculating an actual injury rate we compared the nature of injury and subsequent treatment observed in our series with those reported in a survey of soccer and rugby injuries presenting to a single large accident and emergency department ${ }^{1}$.

An actual injury rate was calculated per 10000 player hours to enable comparison with rates reported in a previous survey of various amateur sports ${ }^{2}$. Assessment of the playing and training time during which the injuries occurred was enabled through consultation with the Camanachd Association who provided accurate records of the fixtures played and an estimation of an average training time.

\section{Results}

A total of 126 injuries were observed in 111 patients with an average age of 24.3 years (range 14-47). The injuries were caused by the caman in 97 cases and the ball in six cases. There were five non contact (twist- 
Table 1. Nature of injuries by site

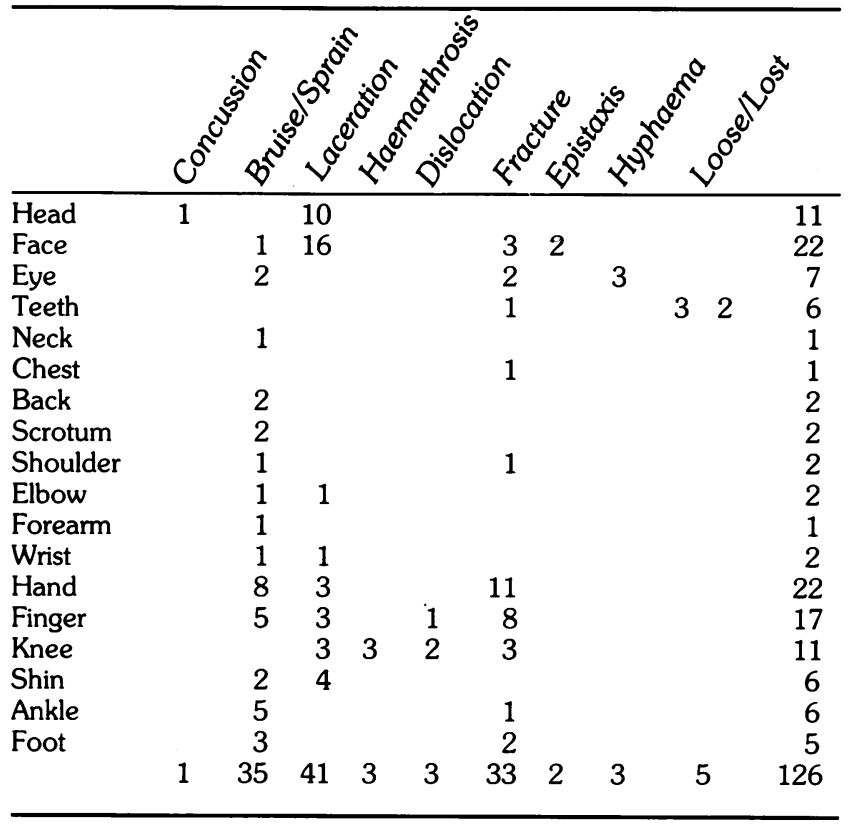

ing or slipping injuries) and three caused by player collision.

Attack and defensive positions were approximately equally involved and one goalkeeper and one referee were injured. Only 11 of the 111 players sustained their injury through illegal play.

The nature of injuries by site are as depicted in Table 1. A wide variety of injuries were observed; 26 of the 41 lacerations involved the head and face, and 19 of the 32 fractures involved the hand and fingers.

It was noted that 95 per cent of the injuries were treated in outpatients. The treatments employed are illustrated in Figure 1. The low internal fixation and manipulation rate demonstrates how the majority of the fractures we observed were undisplaced and thus amenable to conservative treatment.

Only seven cases warranted hospital admission.

Two orthopaedic cases: a proximal tibio-fibular joint dislocation, and one compound finger fracture dislocation.

Two opthalmic cases: one severe hyphaema and one blow-out fracture of the orbit which underwent reconstructive surgery.

Two dental cases: two fractures of the mandible, one of which was bilateral.

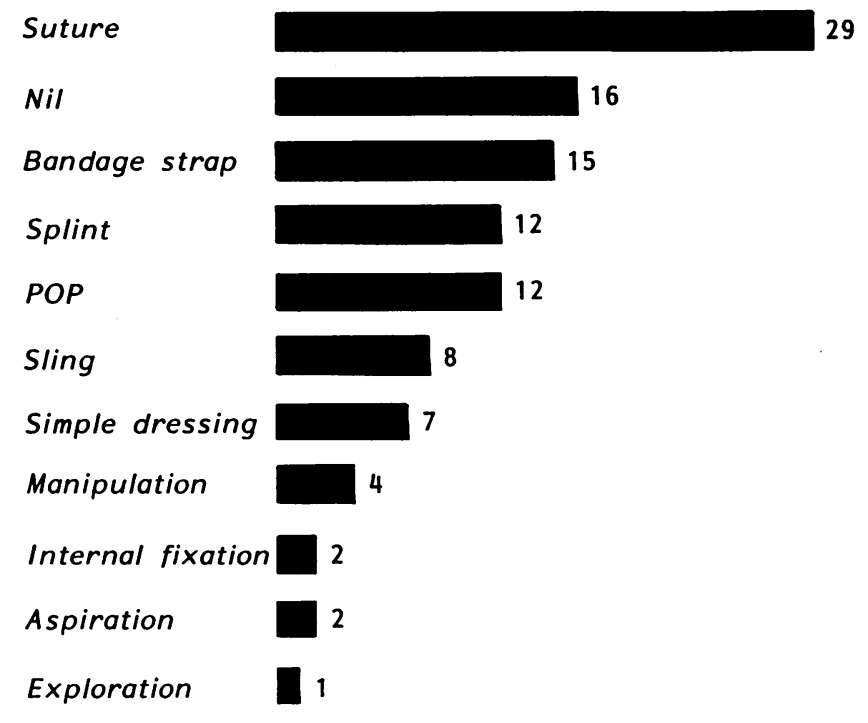

Figure 1. Treatments

One general surgical: a persistent traumatic hydrocele which on exploration was due to a partially severed epididymis.

\section{Discussion}

The number of injuries recorded in this survey is not large. However, by including only those which presented to hospital, we hope to have included all the 'significant' injuries sustained by shinty players in one season. There will no doubt have been some injuries which will have been managed by local general practitioners, particularly in an area such as the Highlands.

Our results show that, while injuries affected nearly every part of the body, the head and the hand predominated. It would appear that the nature and severity of injuries, as judged by the necessary treatment, are not significantly different to those in rugby and soccer as shown in Table 2.

The quantitative assessment of sports injuries is often difficult. However, with the aid of the Camanachd Association we hope to have calculated as accurate a figure as possible (Table 3). Compared with injury rates for other amateur sports, shinty features at the top of the list, with a rate two and a half times that of soccer and nearly three times that of rugby. It is interesting to note that the injury rate in shinty is seven

Table 2. Comparison of injuries sustained in soccer, rugby and shinty

Nature of injury

\begin{tabular}{llccc}
\hline & Bruising & Laceration & Fracture & Dislocation \\
\hline Soccer & $50.9 \%$ & 10.3 & 16.9 & 1 \\
Rugby & 41.5 & 6.2 & 17.6 & 3.1 \\
Shinty & 27 & 32.5 & 26 & 2.3 \\
\hline
\end{tabular}

Nature of treatment

\begin{tabular}{lccccrr}
\hline & Nil & Dressing & Suture & Bandage & POP & Theatre \\
\hline Soccer & $9 \%$ & 6 & 5.8 & 44.3 & 9.6 & 0.1 \\
Rugby & 14.9 & 1.8 & 5.5 & 34.1 & 10.5 & 2.4 \\
Shinty & 14.8 & 7 & 26.8 & 13.8 & 11.1 & 4.6 \\
\hline
\end{tabular}


A survey of shinty injuries in the Highlands 1987-8: J.G.B. Maclean

Table 3. Calculation of injury rate

$\frac{\text { Matches } \times \text { Duration } \times \text { Players per game }}{60}$

$\frac{317 \times 90 \times 24}{60}=11412$

Teams $\times$ Players per team $\times$ Hours training $\times$ Weeks per season Per week

$45 \times 12 \times 2 \times 32=34560$

126 Injuries in 45972 hours

27.04 Injuries per 10000 hours played
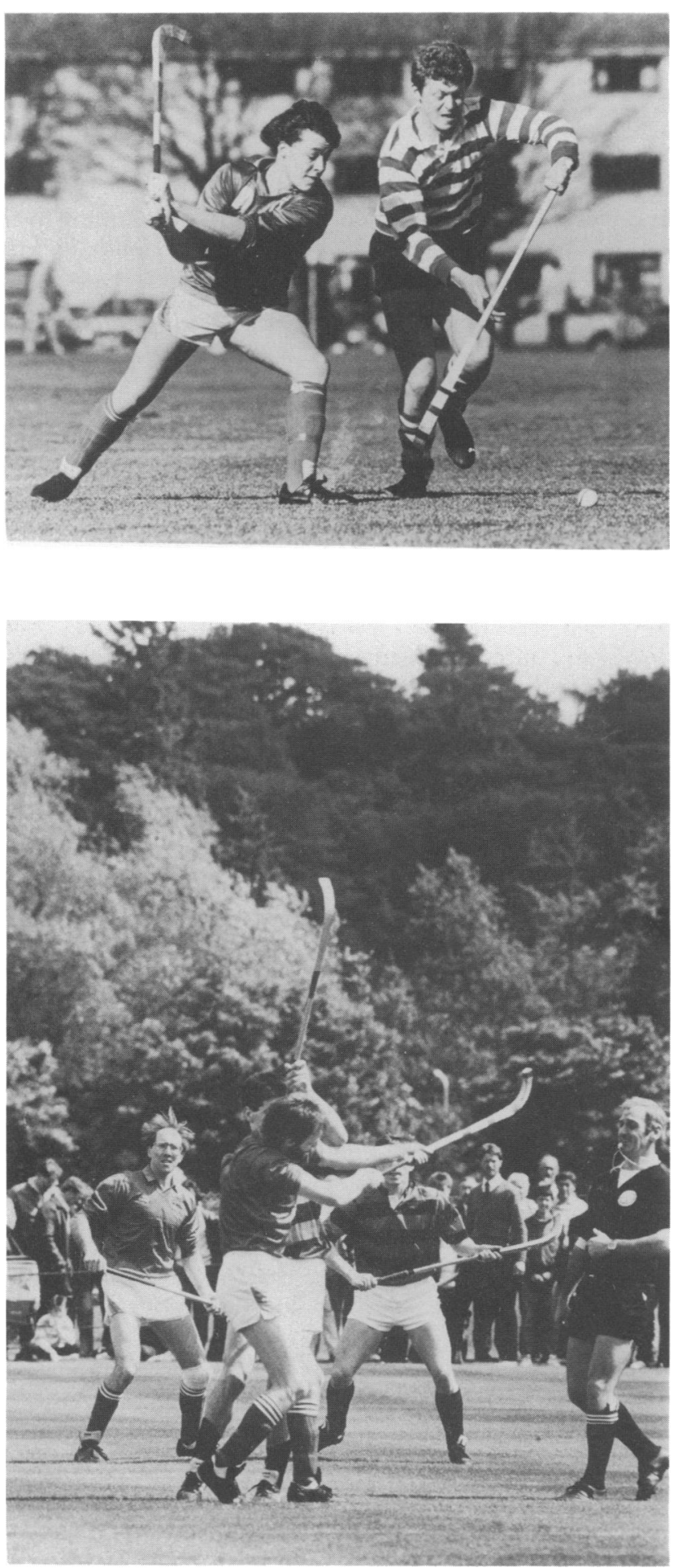

Figures 2-6. Action shots from shinty games
Table 4. Comparison of injury rates

\begin{tabular}{lccc}
\hline & $\begin{array}{c}\text { Injuries/ } \\
10000 \\
\text { hours }\end{array}$ & $\begin{array}{c}\text { \% of injuries } \\
\text { presenting } \\
\text { to hospital }\end{array}$ & $\begin{array}{c}\text { Injuries per } \\
\text { 10 000 playing hours } \\
\text { presenting to hospital }\end{array}$ \\
\hline Football & 36.5 & 30 & 10.95 \\
Rugby & 30.5 & 51 & 15.5 \\
Hockey & 12.5 & 45 & 5.6 \\
Hockey & 10.3 & 34 & 3.5 \\
Cricket & 2.6 & 32 & 0.8 \\
Boxing & 1.4 & 50 & 0.7 \\
Shinty & & & 27.04 \\
\hline
\end{tabular}
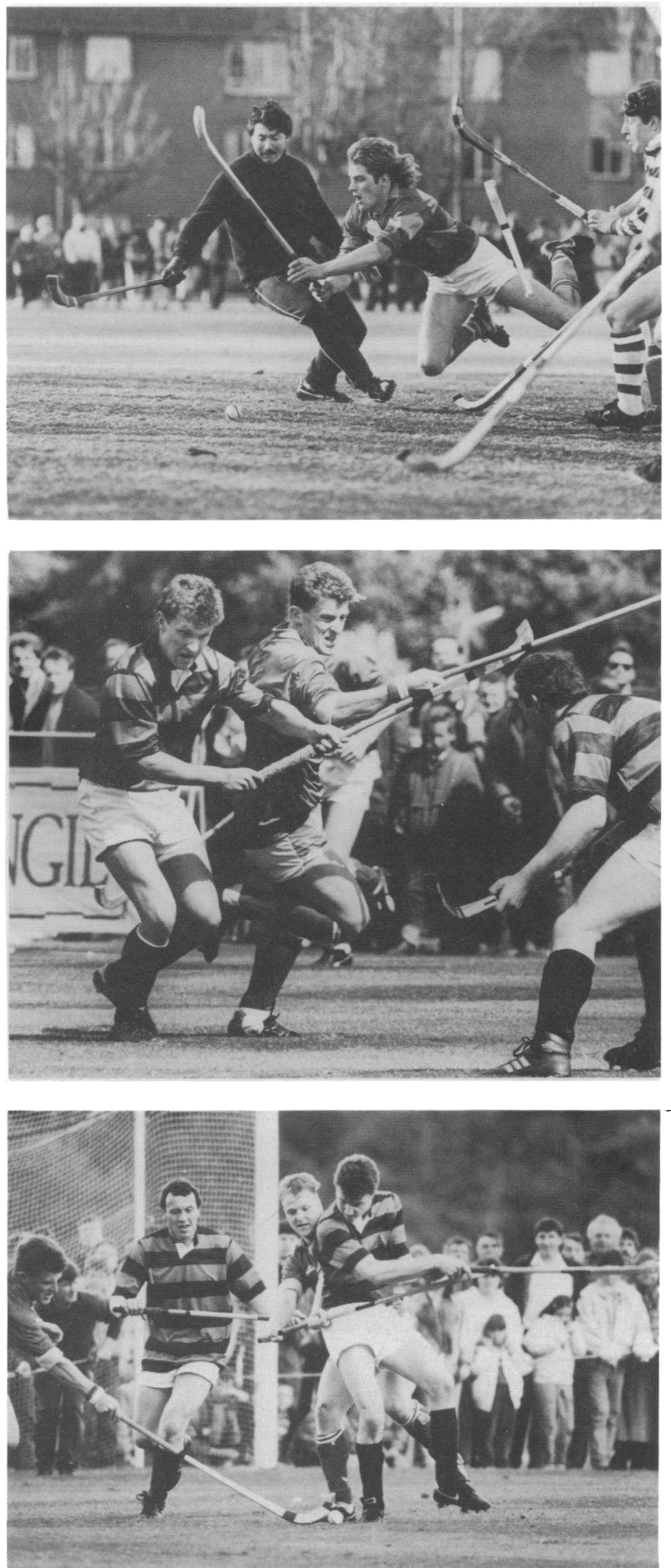

Br. J. Sp. Med., Vol. 23, No. 3 
times that of hockey to which it is clearly related as shown in Table 4.

Despite the comparatively high injury rate we observed in shinty, the subsequent morbidity of these injuries is unlikely to be significant. The importance of this fact cannot be over emphasized as this has obvious financial implications to the players as individuals and to the sport as a whole. Nevertheless, we must ask whether the number of injuries could be reduced without detracting from the game as it is played today.

At present, the only protection worn by players is shin pads. In view of the high incidence of facial and head lacerations and hand and finger fractures, it would seem appropriate to consider protective clothing for these regions, perhaps similar to that worn by players of hurling and men's lacrosse. We are currently investigating the mechanism of the injuries attributable to the caman itself, and hope to comment further on these in a subsequent study.

\section{Acknowledgements}

I would like to acknowledge the help and advice I have received from Mr G.S. Welch, consultant Orthopaedic surgeon in Inverness, without whom this project would probably not have taken place, and Mr D.F. Finlayson, consultant orthopaedic surgeon in Inverness, for his advice throughout the survey.

I would also like to acknowledge the nursing and medical staff of the respective accident and emergency departments in Inverness, Fort William and Oban for their cooperation in performing this survey.

Also the Camanachd Association members, in particular Jack Richmond for his assistance and information throughout the project.

Ewen Wetherspoon, Donald Mackay and Angus McDiarmid for their photographic contribution, and finally the departments of medical illustration at Raigmore Hospital, Inverness and St Bartholomews Hospital, London. I would like to thank CPB Maclean for his editorial assistance.

\section{References}

1 Pickard, M.A.D. et al. Football injuries presenting to an accident and emergency department Health Bulletin $1987,45 / 5,263-7$

2 Weightman, D. and Browne, R.C. Injuries in eleven selected sports Br J Sports Med 1975, 8, 136-141 